\title{
Lebit Enerji Güneş Santralinin Pvsyst Programı ile Analizi
}

\author{
Hamit Kürşat DEMIRYÜREK ${ }^{1}$, Uğur ARİFOĞLU ${ }^{1}$, Mehmet BOLAT ${ }^{2 *}$ \\ ${ }^{1}$ Sakarya Üniversitesi, Elektrik ve Elektronik Mühendisliği, Sakarya \\ ${ }^{2}$ Siirt Üniversitesi, Elektrik ve Elektronik Mühendisliği, Siirt \\ (ORCID: 0000-0002-0152-8793) (ORCID: 0000-0001-8082-5448) (ORCID: 0000-0003-0988-0262)
}

\begin{abstract}
$\ddot{\mathbf{O} z}$
$\mathrm{Bu}$ çalışmada, 200kWp kurulu güce sahip, Lebit Enerji güneş santraline ait bilgiler, PVsyst V6.67-TRİAL programına aktarılmış, simüle edilmiş ve gerçek üretim verileri ile simülasyon verileri karşılaştırılmıştır. Simülasyon sonucunda elde edilen rapor ile sisteme ait kayıplar (termal kaybı, kablolama kaybı, gölgeleme kaybı, uyumsuzluk kaybı, tozlanma ve karlanma kaybı, panel kaybı, inverter kaybı vb.) analiz edilmiştir. Yapılan analizde, simülasyon sonuçları ile gerçek üretim değerleri arasında yaklaşı $\% 0.56$ ' 1 k bir fark olduğu görülmüştür. $\mathrm{Bu}$ sonuç, tasarım aşamasında olan PV sistemleri için, yapılan fizibilite çalışmalarına büyük katkı sağlayabileceği gibi, hali hazırda kurulu olan PV sistemlerin daha verimli hale getirilebilmesi için, yapılacak olan revizyon çalışmalarına 1şık tutabilir.
\end{abstract}

Anahtar kelimeler: Şebekeye bağlı PV sistem, PVsyst, solar radyasyon, simülasyon, kayıplar.

\section{Analysis of Lebit Energy Solar Power Plants with Pvsyst Program}

\begin{abstract}
For the purposes, actual production values and simulation values were compared with using the datas of $200 \mathrm{kWp}$ Lebit Enerji solar power plant, which was transferred and simulated to PVsyst V6.67-TRIAL program. Systematic losses (temperature and wind loss, cable loss, shading loss, loss of incompatibility, loss of dust and snow, loss of panel, loss of inverter, etc.) were analyzed by the report obtained as a result of the simulation. In the analysis shows that, there is a difference about $\% 0.56$ between the simulation results and the actual production values. This will provide big convenience for feasibility studies of PV systems that are in the design step, on the other hand it can be guide to make revision more effective PV systems.
\end{abstract}

Keywords: Grid connected PV system, PVsyst, solar radiation, simulation, losses.

\section{Giriş}

Nüfusun artışı ve teknolojinin hızla gelişmesiyle birlikte, enerji ihtiyacı, gün geçtikçe daha da artmaktadır. Dünyada kullanılmakta olan enerjinin büyük bir çoğunluğu, fosil yakıtlardan elde edilmektedir. Dünyada enerji ihtiyacı yılda ortalama \%4-5 oranında artarken fosil yakıt rezervi daha yüksek oranda azalmaktadır [1]. Ayrıca, fosil yakıtla enerji elde edilirken, çevreye her geçen gün daha fazla zarar verilmektedir. Hem fosil yakıt rezervlerinin gün geçtikçe azalması hem de fosil yakıtların çevreye vermiş olduğu zararlar, yenilenebilir enerji kaynaklarına yönelmeyi zorunlu kılmıştır [2].

Yenilenebilir enerji kaynağı, enerji kaynağından alınan enerjiye eşit oranda veya kaynağın tükenme hızından daha çabuk bir şekilde kendini yenileyebilmesi olarak tanımlanır. Yenilenebilir enerji kaynakları, hidroelektrik, jeotermal, rüzgâr, biokütle ve güneş olarak sıralanabilir [3]. Yenilenebilir enerji kaynaklarından güneş enerjisi, kolay ve hızlı kurulumu ile büyük ve küçük ölçekli olabilmesi, son yüzyıllarda dikkatleri üzerinde toplamaktadır. Yapılan araştırmalar sonucunda, dünyada bilinen bütün enerji kaynaklarından, elde edilebilecek enerji, güneşin sadece üç günde yaymış olduğu enerjiye eşittir. Ayrıca, güneş enerjisinin diğer yenilebilir enerji kaynaklarına kıyasla, çevreye daha az zarar vermesi,

"Sorumlu yazar: mehmetbolat@ siirt.edu.tr

Geliş Tarihi:25.11.2019, Kabul Tarihi: 09.04.2020 
güneş enerjisi kullanımı sırasında, karbondioksit ve diğer sera gazlarından hiçbirini üretmemesi de önemli bir etkendir [1,2].

\subsection{Dünya'da Güneş Enerjisi Durumu}

Dünyada, güneş enerjisi üretiminde Almanya, Çin ve Japonya başta gelen ülkelerdir. Güneş enerjisini kullanan bu ülkelere baktığımızda, bazıları güneş ışınları potansiyeli bakımından öne çıkarken, bazıları ise sahip oldukları teknoloji birikiminden dolayı öne çıkmaktadır. Şekil 1.1'de verilen dünya güneş enerjisi potansiyeli haritasında, koyu kırmızı renkli bölgelerde güneş enerjisi potansiyeli yüksekken, mavi renkli bölgelere doğru gidildikçe güneş enerji potansiyeli azalmaktadır.

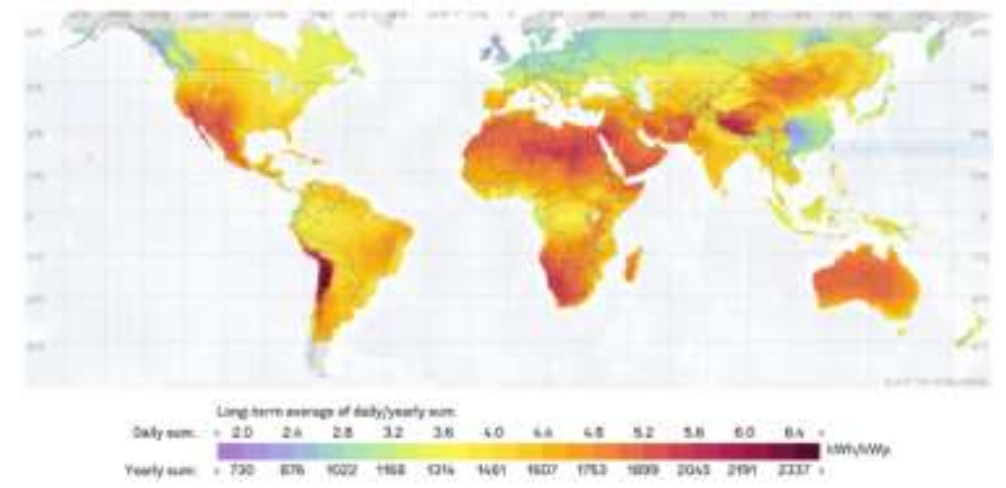

Şekil 1.1. Dünya güneş enerjisi potansiyeli haritası [4]

Dünyada güneşten elde edilen enerji miktarına bakıldığında, 2016 yılında üretilen enerji 2015 yılına kıyasla $\% 50$ arttığı görülmektedir. Brüksel'de düzenlenen enerji zirvesinde, dünyada enerji kapasitesinin 2016 yılında 305GW değerlerine kadar ulaştığ şekilde incelendiğinde, Almanya toplamda $70 \mathrm{GW}$ güneş enerjisi üretimi kapasitesi ile zirvede bulunmaktadır [5].

\subsection{Türkiye'de Güneş Enerjisi Durumu}

Coğrafi konumu itibariyle kuzey yarım kürede yer alan Türkiye, sahip olduğu güneş enerji potansiyeli açısından, diğer ülkelere göre oldukça yüksek potansiyele sahiptir. Her ne kadar bu enerji potansiyelini günümüze kadar, yeterli kullanılmasa da çıkartılan yönetmelikler ve teşvikler sayesinde ilgi gün geçtikçe artmaktadır [5, 6].

Türkiye'de, 2014 y1lında 40 MW olan kurulu güç kapasitesi, 2015 y1lında 249 MW'a ve 2016'da ise $830 \mathrm{MW}$ seviyesine ulaşmıştır [7]. Türkiye'deki toplam kurulu güç kapasitesinin ancak yaklaşık \%1'i güneş enerjisinden elde edilebilmektedir. Türkiye'de 2010 y1lı öncesinde, güneş sistemleri, genellikle termal amaçlı kullanılırken, 2010 yılından itibaren, güneş enerjisinden elektrik üretimindeki çalışmalar artmaya başlamıştır. Ulusal Yenilenebilir Enerji Eylem Planı kapsamında 2023 yılı için 1sıtma ve soğutma amaçlı enerji ihtiyacının en az yüzde 15'inin yenilenebilir enerji kaynaklarından sağlanması amac1 doğrultusunda, güneş enerjisinin daha etkin, verimli, teknolojik ve yenilikçi bir biçimde kullanılması planlanmaktadır. 2023 yılı brüt elektrik talebinin 500 bin MW olacağı öngörüsü altında, Türkiye tüm güneş potansiyelini kullanmak koşuluyla, 2023 yılına gelindiğinde, elektrik talebinin tamamını sadece güneş enerjisinden karşılayabilecektir. Ancak, mevcut imkân ve maliyetlerin bu öngörünün gerçekleşmesine olanak sağlayamayacağı açıktır. Enerji ve Tabii Kaynaklar Bakanlığı (ETKB) tarafindan yapılan tahminler 2019 y1lı için güneş enerjisinde 3 bin MW'lik elektrik üretimi gerçekleştirilmesi ve bu rakamın 2023 yılında 5 bin MW'a ulaştırılması yönündedir [7]. Şekil 1.2.'de verilen Türkiye'nin güneş enerji potansiyeli haritasına bakıldığında, güneş enerjisi potansiyeli bakımından Güneydoğu Anadolu ve Akdeniz bölgeleri ilk sıralarda yer alırken, Marmara ve Doğu Karadeniz bölgeleri ise ülkenin en az güneş alan bölgeleri arasında bulunmaktadır. 


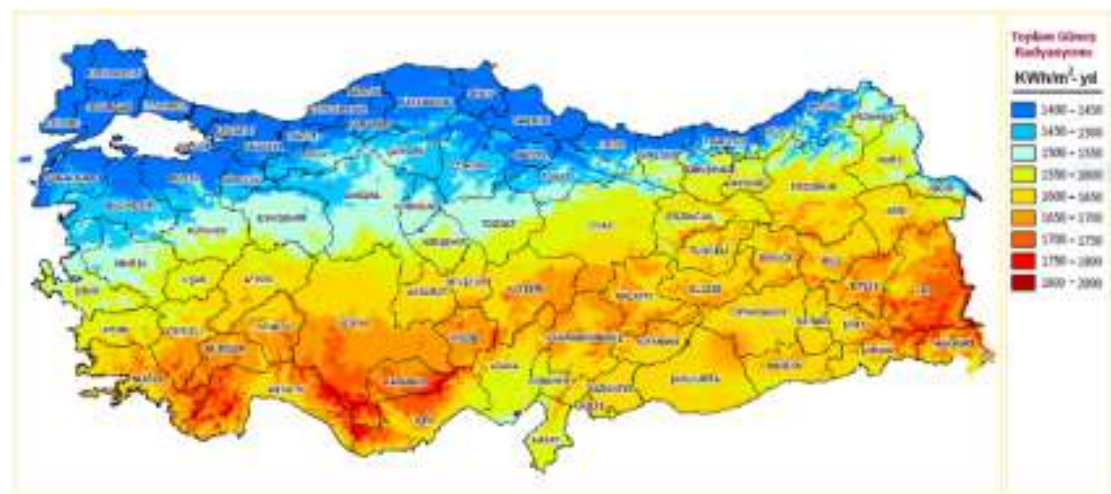

Şekil 1.2. Türkiye'nin güneș enerjisi potansiyeli haritası [8]

\subsection{Siirt İli Güneş Enerjisi Durumu}

Güneydoğu Anadolu bölgesinde bulunan Siirt ili, coğrafi konumu açısından, ülkemizdeki diğer illere göre oldukça yüksek güneş enerjisi potansiyele sahiptir. Şekil 1.3.'te verilen Siirt ili güneş enerji potansiyeli haritası, Şekil 1.4.'de ise Siirt ili global radyasyon değerleri ve güneşleme süreleri grafiği verilmiştir.

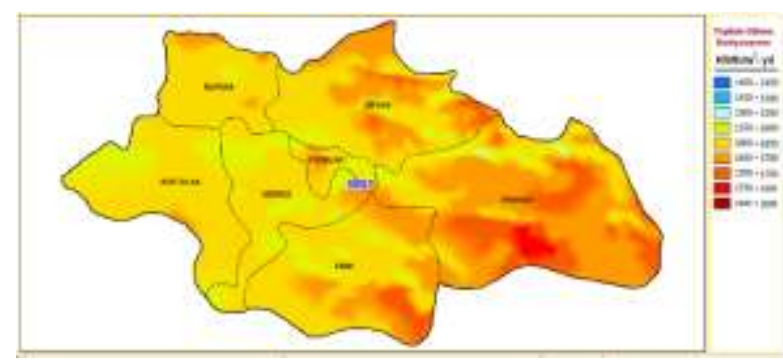

Şekil 1.3. Siirt ili güneş enerjisi potansiyeli haritası [8]

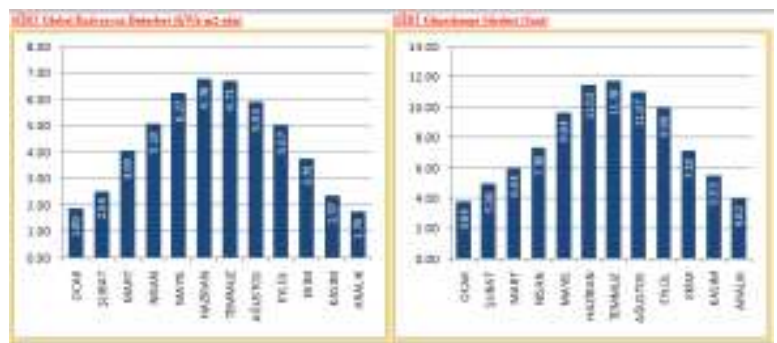

Şekil 1.4. Siirt ili global radyasyon değerleri ve güneşleme süreleri grafiği [8]

\section{Materyal ve Metot}

PV sistemlerin analizi için, PVsyst, Homer, RETScreen, PVGIS, PVSOL Expert gibi birçok simülasyon programı mevcuttur. Ancak yapılan literatür taraması ve araştırmalar sonucunda, geniş seçim yelpazesine sahip, PV sistem elemanlarını altyapısında barındırarak hızlı ulaşım imkanı sağlaması, PV sistemlerde bulunan kayıpların ayrıntılı olarak sisteme aktarılabilmesi, varsayılan seçim şartlarının literatüre uygun olması, 3 boyutlu çizim özelliği ile gölgeleme kayılarının tespit edilebilmesi, ekonomik analiz yapılabilmesi ve gerçek sonuçlar ile simülasyon sonuçları arasında çok az bir fark olması bu çalışmada PVsyst programının kullanımına karar verilmiştir [9-28].

PVsyst programı Cenevre Üniversitesi tarafından geliştirilmiş olup, program ile şebekeye bağlı, şebekeden bağımsız, pompa ve DC üretim sistemlerinin ayrı ayrı tasarımı yapılabilmektedir.

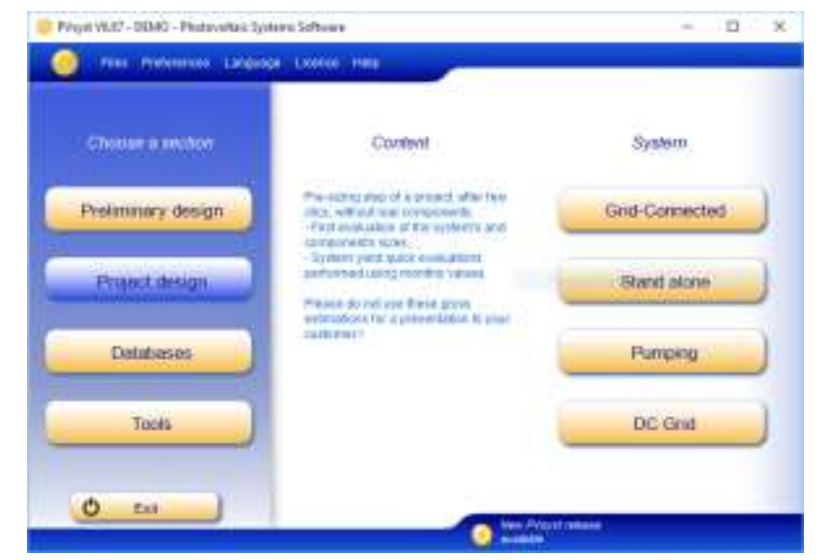

Şekil 2.1. PVsyst programı ana ekran görüntüsü 
Lebit Enerji güneş santrali şebeke bağlı bir güneş santralidir. Lebit Enerji güneş santralinin PVsyst programı ile simülasyonu 8 ana adımda yapılmışıı. Bu adımlar aşağıda belirtilmiştir [29].

\subsection{Proje Bölümü}

Santralin kurulacağı yerin PVsyst programına tanıtılıp, meteorolojik bilgiler aktarılmaktadır.

\subsubsection{Konum}

Lebit Enerji güneş santrali Siirt ili Merkez İlçesine bağl1 Bağtepe mevkiinde, (N 37.945; E 41.973) koordinatlarında kuruldu. Lebit Enerji güneş santraline ait Şekil 2.2.'de uydu görüntüsü ve Şekil 2.3'te yakından görünümü verilmiştir.

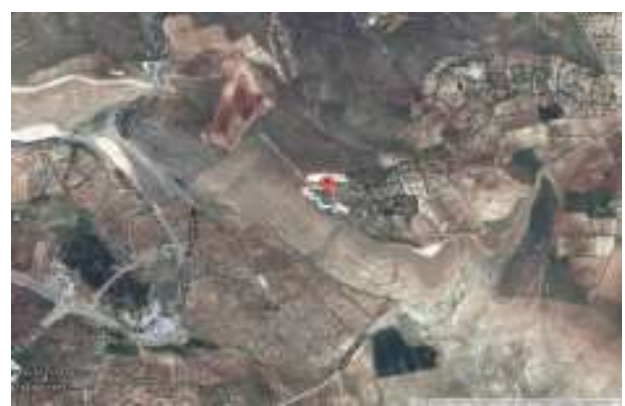

Şekil 2.2. Lebit Enerji güneş santrali uydu görüntüsü

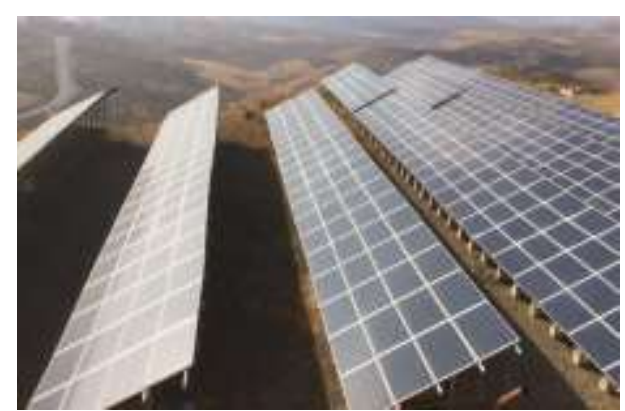

Şekil 2.3. Lebit Enerji güneş santrali görünümü

\subsubsection{Meteorolojik Verilerin Aktarılması}

Lebit Enerji güneş santralinin bulunduğu konuma ait meteorolojik veriler PVsyst programının veri tabanında bulunmamaktadır. Bu sebeple ilk adım olarak Lebit Enerji güneș santralinin bulunduğu konuma ait meteorolojik bilgilerin sisteme aktarılması gerekir. Bu işlem, Databases bölümünden Geographical Sites sekmesi altında Şekil 2.4 ve Şekil 2.5' de verilen adımlar yerine getirilerek yapılır.

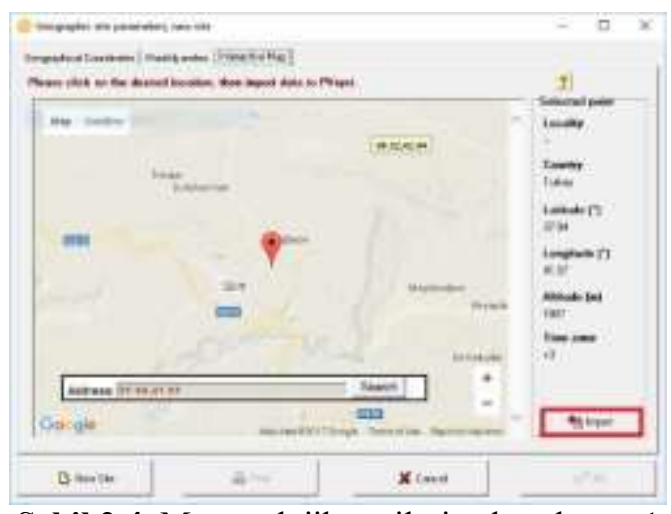

Şekil 2.4. Meteorolojik verilerin aktarılması-1

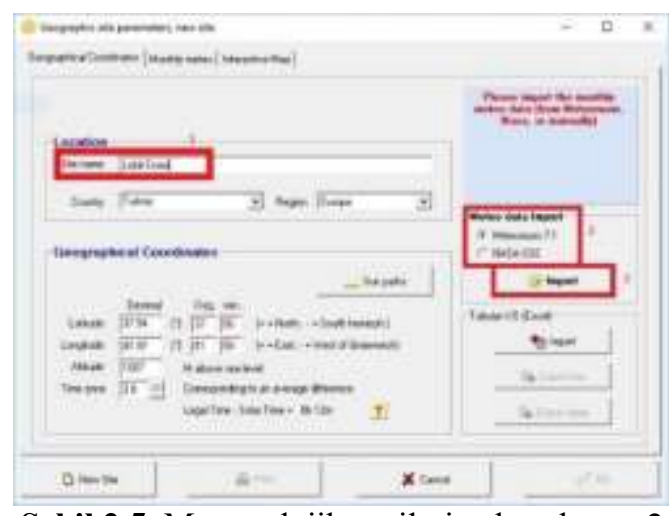

Şekil 2.5. Meteorolojik verilerin aktarılması-2

\subsection{Sistem Bölümü}

Güneş paneli, inverter ve seri-paralel dizilere ait bilgilerinin programa nasıl tanıtıldığı açıklanmaktadır. Sisteme bölümüne ait ekran görüntüsü Şekil 2.6.'da verildi. 


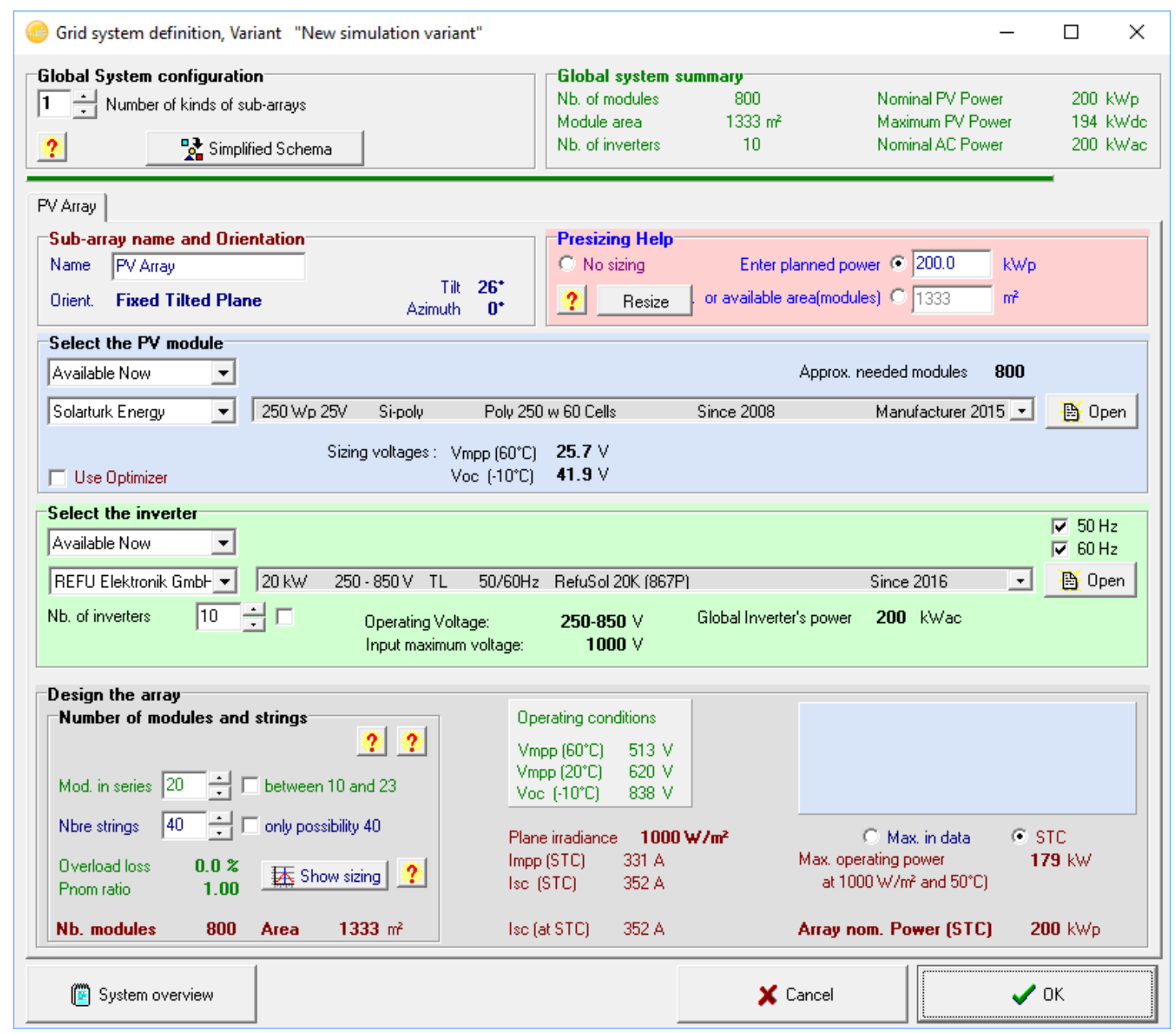

Şekil 2.6. Lebit Enerji güneş sanrali sistem bilgileri

\subsubsection{Güneş Paneli}

Fotovoltaik hücreler (Photovoltaic, PV) 1ş1k enerjisini elektrik enerjisine dönüştüren yarı iletken malzemelerden meydana gelmektedir. Fotovoltaik hücrelerinin şekilleri, kare, dikdörtgen veya daire biçiminde, alanları $100 \mathrm{~cm}^{2}$ civarında, kalınlıkları ise $0,2-0,4 \mathrm{~mm}$ arasındadır.

Şekil 2.7.'de, fotovoltaik hücreler seri ve paralel bağlanarak güneş panellerini (modül) meydana getirir. Güneş panelleri seri bağlanarak dizileri (string), stringler ise paralel bağlanarak dizeleri (array) meydana getirir.

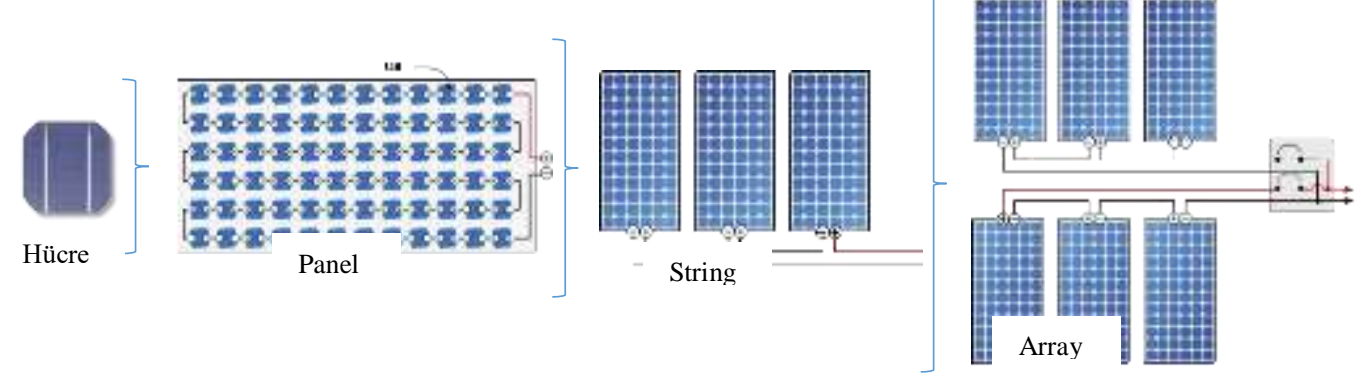

Şekil 2.7. Fotovoltaik hücreler

\subsubsection{Fotovoltaik Hücrelerinin Çalışma İlkesi}

Fotovoltaik hücrelerinin çalışma ilkesi, Fotovoltaik (Photovoltaic) olayına dayanır. Fotovoltaik olayı ilk kez 1839 yılında Becquerel tarafindan bulmuştur. Fotovoltaik olayda fotonlar elektronlara çarpar ve 
serbest yük çiftleri oluşturur, bu sayede geride pozitif yüklü bir alan kalır. Bir taraf negatif yük diğer taraf ise pozitif yük ile yüklendiğinden, hücre arasında gerilim farkı meydana gelir.

\subsubsection{Fotovoltaik Hücre Eşdeğer Modeli}

Fotovoltaik hücrelerinin eşdeğer devre modeli, ilk olarak Lorenzo tarafindan 1994 yılında tanımlanmıştır. Şekil 2.8.' de verilen bu eşdeğer devre modeli, bir akım kaynağı, akım kaynağına paralel bir diyot, diyota paralel bir topraklama direnci ve tüm bunlara seri bağlı bir iç dirençten oluşur [30].

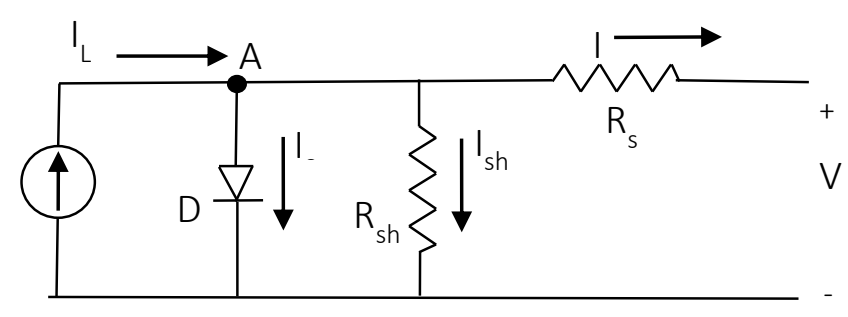

Şekil 2.8. Güneş pili eşdeğer devresi

Şekil 2.8.'de verilen devrede, A noktasına Kirchoff Akım Yasasını uygulanırsa;

$I_{L}=I_{0}+I_{s h}+I$

denklemi elde edilir. Diyot gerilimi ve diyot akımı;

$\mathrm{V}_{\mathrm{d}}=\mathrm{V}+\mathrm{R} \cdot \mathrm{I}$

$I_{d}=I_{0}\left(e^{\frac{q \cdot V_{d}}{n \cdot k \cdot T}}-1\right)=I_{0}\left(e^{\frac{q \cdot\left(V+R_{S} \cdot I\right)}{n \cdot k \cdot T}}-1\right)$

olarak ifade edilir. Şekil 2.8.'de verilen devrede, diyota paralel olan $\mathrm{R}_{\mathrm{sh}}$ direncinin üzerinden geçen akım ise;

$I_{\text {sh }}=\frac{V_{d}}{R_{s h}}=\frac{V+R_{s} \cdot I}{R_{s h}}$

olarak elde edilir. (Denklem 3) ve (Denklem 4), (Denklem 1)'de yerine konulursa; (Denklem 3.5)'te verildiği gibi elde edilir.

$I=I_{L}-I_{0}\left(e^{\frac{q \cdot V_{d}}{n \cdot k \cdot T}}-1\right)-\frac{V+R_{s} \cdot I}{R_{s h}}$

(Denklem 5)'te paralel direnç $\mathrm{R}_{\text {sh }}$ çok küçük olduğu için, ihmal edilebilir. (Denklem 5)'ten V değeri çekilirse;

$\mathrm{V}=\frac{\mathrm{n} \cdot \mathrm{k} \cdot \mathrm{T}}{\mathrm{q}} \cdot \ln \left[\frac{\mathrm{I}_{\mathrm{L}}+\mathrm{I}_{0}-\mathrm{I}}{\mathrm{I}_{0}}\right]-\mathrm{R}_{\mathrm{S}} \cdot \mathrm{I}$

(Denklem 6)'te verilen fotovoltaik hücrenin uçlarındaki gerilim değeri elde edilir.

\subsubsection{Güneş Paneli Eşdeğer Modeli}

Fotovoltaik hücreler güneş sistemlerinin en küçük birimi olup tek başına çok küçük değerde $(0.5 \mathrm{~V})$ gerilim üretirler. Haliyle, bu küçük değerdeki gerilim tek başına kullanılamaz. Kullanılabilir bir değerde güç elde edebilmek için fotovoltaik hücrelerinin seri ve paralel bağlanması gerekmektedir. Bu şekilde elde edilen yapıya güneş paneli (modül) denir. Şekil 2.9.'de verilen güneş paneli eşdeğer devresinde $\mathrm{N}_{\mathrm{s}}$ 
seri bağlı hücre sayısını, $\mathrm{N}_{\mathrm{p}}$ ise paralel bağlı hücre sayısını ifade eder. Seri hücre sayısı $\left(\mathrm{N}_{\mathrm{s}}\right)$ panel gerilimi artırırken, paralel hücre sayısı $\left(\mathrm{N}_{\mathrm{p}}\right)$ panel akımını artırır [30].

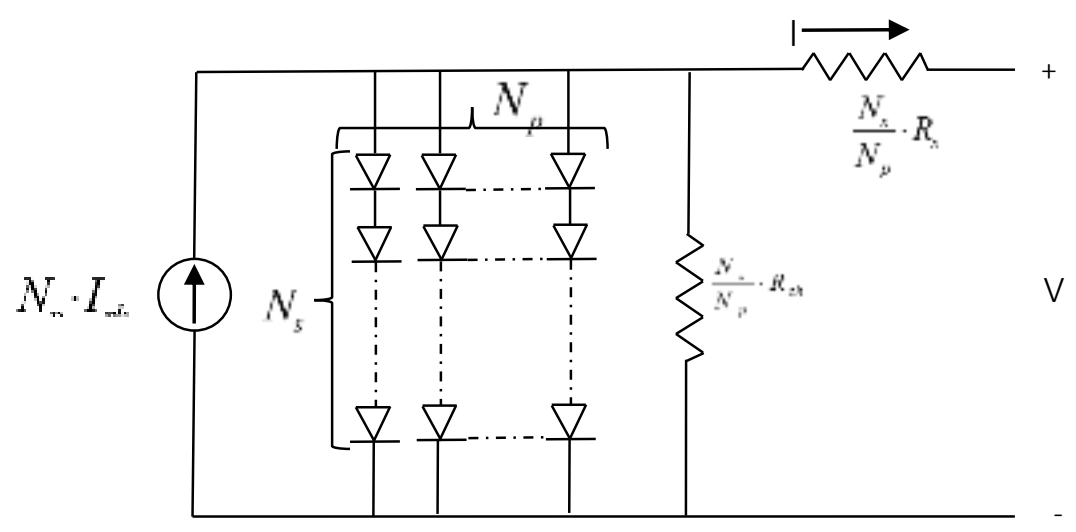

Şekil 2.9. Güneş paneli eşdeğer modeli

Şekil 2.9.'de verilen devrede, panel akım denklemi;

$I=N_{p} \cdot I_{L}-N_{p} \cdot I_{L}\left[e^{\frac{\frac{V}{N_{s}}+\frac{I \cdot R_{s}}{N_{p}}}{n \cdot k \cdot T}}-1\right]-\frac{\frac{N_{p} \cdot V}{N_{s}}+R_{s} \cdot I}{R_{s h}}$

olarak elde edilir.(Denklem 7)'de paralel direnç $\mathrm{R}_{\text {sh }}$ çok küçük olduğu için ihmal edilebilir. (Denklem 3.7)'de V değeri çekilirse, (Denklem 8)'te verilen güneş panelinden elde edilecek gerelim değeri elde edilir.

$V=\frac{N_{S} \cdot n \cdot k \cdot T}{q} \cdot \ln \left[\frac{\mathrm{I}_{L}+I_{0}-I+N_{p}}{N_{p} \cdot I_{0}}\right]-\frac{N_{S}}{N_{p}} \cdot R_{S} \cdot I$

Lebit Enerji güneş santralinde, Tablo 2.1.'de katalog bilgileri verilen SolarTürk marka güneş panellerinden toplam 800 adet kullanılmıştır. 20'şer adet güneş paneli seri bağlanarak 40 adet string oluşturulmuş, 4'er adet string paralel bağlanarak 10 adet array meydana getirilmiştir [1].

Tablo 2.1. SolarTürk Güneş Paneli Katalog Bilgileri

\begin{tabular}{lclc}
\hline Elektriksel Özellikler & \multicolumn{3}{c}{ Teknik Bilgiler } \\
\hline Nominal Güç (Wp) & 250 & Hücre Sayısı & 60 (6x10) \\
Nominal Güç Toleransı (Wp) & $-0 /+5$ & Hücre Tipi & Polikristal \\
Nominal Güç Voltajı (V) & 31.28 & Hücre ölçüsü (mm) & $156 \times 156$ \\
Nominal Güç Akımı (A) & 8.01 & Panel Ölçüsü UxExY (mm) & $1665 \times 1001 \times 42$ \\
Kısa Devre Akımı (A) & 8.66 & Ağırlık (kg) & 19 \\
Açık Devre Voltajı (V) & 37.66 & Bağlantı Tipi & Tyco \\
Maksimum Sistem Gerilimi (V) & 1000 & Diyot Akımı (A) & 5 \\
\hline
\end{tabular}

\subsection{2. İnverter}

Lebit Enerji güneş santralinde Tablo 2.2.'de katalog bilgileri verilen REFUsol 020K marka inverterden her array çıkışına bir adet konulmak üzere toplam 10 adet kullanılmıştır. Montajı, sevkiyatı ve bakımı açısından kolaylık sağladığı için dizi inverter tercih edilmiştir [1]. 
Tablo 2.2. REFUsol $020 \mathrm{~K}$ İnverter katalog bilgileri

\begin{tabular}{lclc}
\hline DC DATA & \multicolumn{3}{c}{ AC DATA } \\
\hline Max. PV Pover (kW) & 21.2 & Rated AC power $(\mathrm{kW})$ & 19.2 \\
MPPT range $(\mathrm{V})$ & $480 \ldots 850$ & Max. AC power $(\mathrm{kW})$ & 19.2 \\
Max. DC voltage (V) & 1000 & AC grid connection $(\mathrm{V})$ & 400 \\
Max. DC current (A) & 41 & Max. AC current $(\mathrm{A})$ & 29 \\
MPP tracking & one fast & Cosǿ & $0.9 \mathrm{i} . .0 .9 \mathrm{c}$ \\
Number of DC connect. & 6 & THD & $\% 1.8$ \\
DC-disconnection switch & Evet & Max. efficiency & $\% 98.2$ \\
İnternal overvoltage prt. & Tip 3 & İnfeed strating at $(\mathrm{W})$ & 20 \\
\hline
\end{tabular}

\subsection{Yönlendirme Bölümü}

Güneş paneli ve azimuth açısı bilgilerinin programa girişi tanıtılmaktadır. Lebit Enerji güneş santralinde; hareketli taşıyıcı panel destek yapılarının, kurulum maliyeti, bakımı ve doğal hava koşulları göz önünde bulundurulduğunda sabit panel taşıyıcı destek yapıları kullanımı tercih edildi. Yapılan ölçümler sonucunda, yıllık maksimum ışımanın elde edilmesi için, Şekil 2.10.'da verildiği gibi, panel açısı $26^{\circ}$ ve azimuth açısı $0^{\circ}$ olarak belirlenmiştir $[3,31]$.

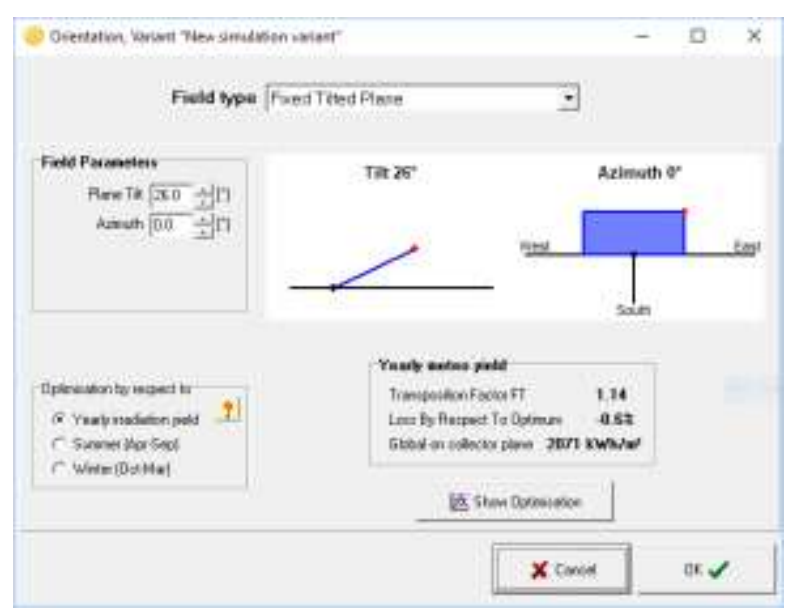

Şekil 2.10. Panel açısı ve Azimuth açısı ekran görüntüsü

PVsyst programında yönlendirme ve sistem bölümüne ait veriler sisteme tanıtıldıktan sonra diğer bölümlere ait verileri sisteme aktarmadan da sistemin varsayılan değeri alınarak sistemdeki verilere göre simülasyonun yapılmasına izin verir. Ancak, ayrıntılı bir analiz yapılmak istenirse gölgeleme, kayıplar ve horizon bilgileri girilir.

\subsection{Gölgeleme Bölümü}

Bu bölümde PVsyst programı ile 3D boyutlu olarak santralin gölgeleme hesapları yapılmaktadır. Lebit Enerji güneş santralinin kurulu olduğu yerde herhangi bir gölgelemeye sebebiyet verecek nesne olmamasına rağmen, panellerin diziliminden kaynaklanan bir gölgeleme olabileceğini düşünerek, Şekil 2.11.'de görüldügü gibi üç boyutlu çizimi yapılarak sisteme aktarıldı. 


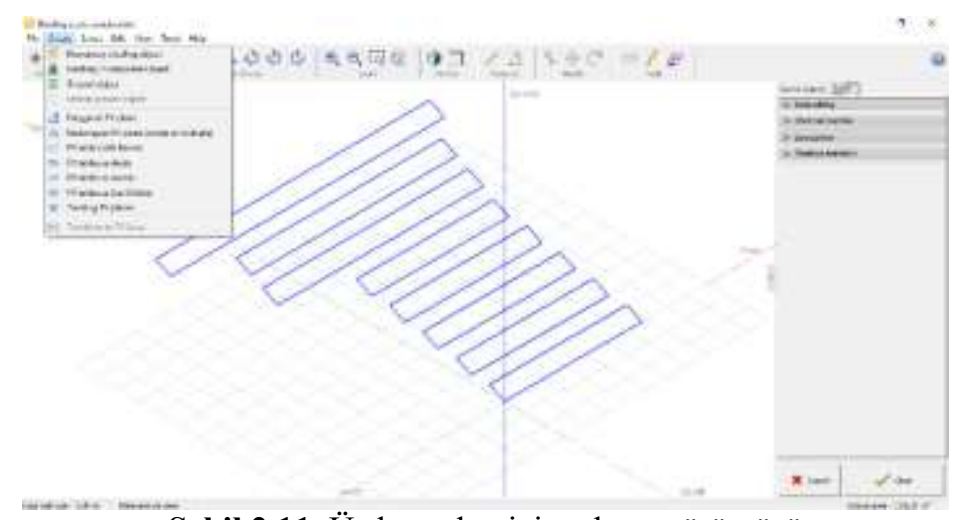

Şekil 2.11. Üç boyutlu çizim ekran görüntüsü

\subsection{Kayıplar Bölümü}

Bu bölümde, Kablo kayıpları, panel kayıpları, tozlanma kayıpları gibi santral kayıplarının programa nasıl girildiği anlatılmaktadır. Şekil 2.12.'de termal (sıcaklık) kayıpları, omik kayıpları (DC kablolama, AC kablolama ve Trafo bağlantı kablolarında kaynaklanan), panel kayıpları, uyumsuzluk kayıpları, tozlanma/karlanma kayıpları, yansıma kayıpları, harici ekipman kayıpları (lamba, kamera, klima vb.), panel yaşlanma kayıpları ve arıza bakım kayıpları olarak sisteme aktarılır.

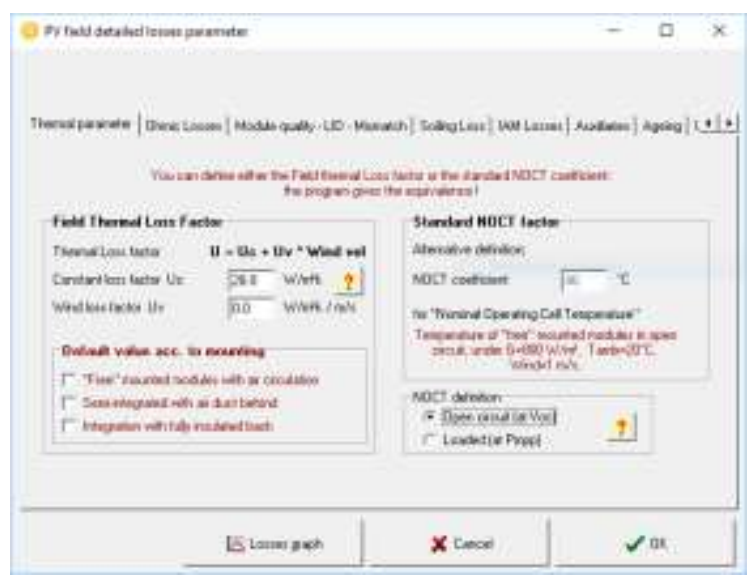

Şekil 2.12. Kayiplar bölümü ekran görüntüsü

\subsection{Horizon (Ufuk Çizigisi) Bölümü}

Bu bölümde, ufuk çizgisinin programa tanıtılması açılanmaktadır. Lebit Enerji güneş santraline ait ufuk çizgisine ait bilgiler sisteme aktarıldığında Şekil 2.13.' deki ekran görüntüsü elde edilir.

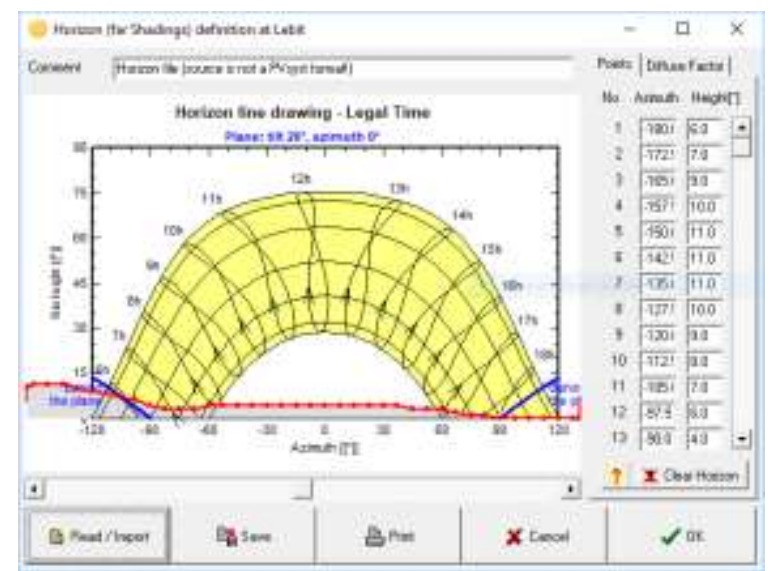

Şekil 2.13. Horizon bölümü ekran görüntüsü 


\subsection{Simülasyon Bölümü}

Santrale ait bütün verilerin rapor ve tablolar halinde analiz anlatılmaktadır. Ana ekran üzerindeki report sekmesine tıklandığında, Lebit Enerji güneş santralinin kurulum yeri bilgilerine, panel açısı bilgisine, panel ve inverter bilgilerine, seri ve paralel bağlı panel bilgisine, PV sistem kayıp bilgilerine (termal, tozlanma, yansıma, uyumsuzluk, vb.), horizon (ufuk çizgisi) veri ve grafiğine, 3 boyutlu çizime ve gölgeleme kaybı grafiği ile PV sisteminin, üretim verilerine ve performans bilgisine ve enerji akış diyagramına ulaşı1ır.

\section{Bulgular ve Tartışma}

Lebit Enerji güneş santraline ait üretim değerleri ile PVsyst programı ile elde edilen simülasyon değerlerinin karşılaştırılması, Şekil 3.1.'de verilmiştir. Şekil 3.1.'de verilen tablo incelendiğinde; Lebit Enerji güneş santralinde, bir y1l boyunca toplamda 319,1 MW enerji üretilmesine karşılık, PVsyst programı 320,9 MW enerji üretilebileceğini öngörmüştür. Üretim değerleri ile simülasyon değerleri arasında sadece $1.8 \mathrm{MW}$ yani \%0.56' lık bir fark bulunmaktadır.

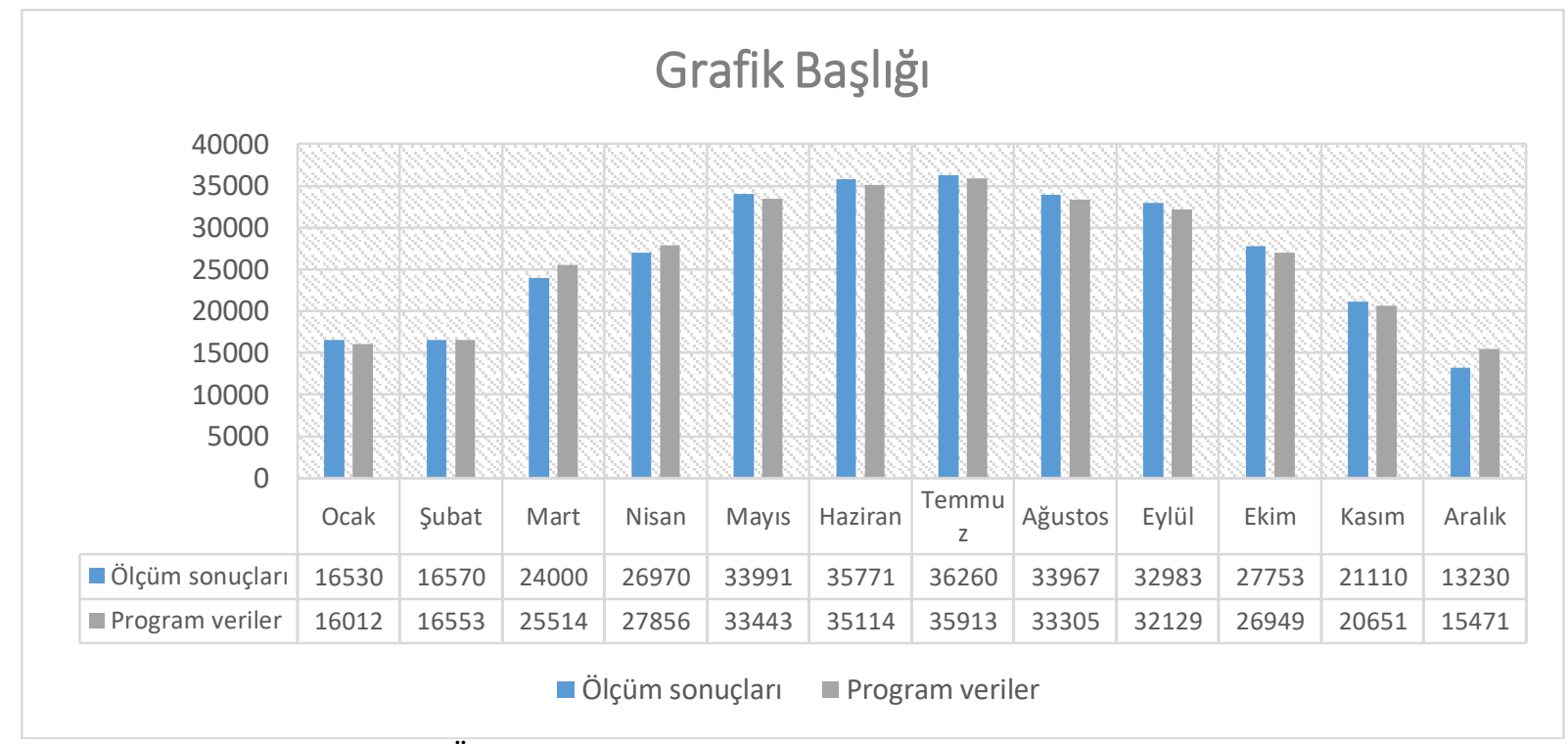

Şekil 3.1. Üretim değerleri ile simülasyon değerlerinin karşılaş̧ırılması

Ocak, Mayıs, Haziran, Temmuz, Eylül, Ekim ve Kasım aylarında üretim değerleri simülasyon değerlerinden yüksek iken, Şubat, Mart, Nisan, Ağustos ve Aralık aylarında simülasyon değerleri üretim değerlerinden yüksek çıkmıştır. Üretim değerleri ile simülasyon değerleri arasındaki fark, en az Şubat ayında iken, en fazla Aralık ayında oluşmuştur. Aralık ayında meydana gelen bu fark, yağan karın birikintiye sebep olması ve temizleme işleminin gecikmesinden kaynaklanmıştır. En fazla üretim 36,260 MW ile Temmuz ayında, en düşük üretim ise 13,230 MW ile Aralık ayında olmuştur. Bu durumun sebebi de en fazla ışımanın Temmuz ayında, en az ışımanın ise Aralık ayında elde edilmesidir.

Şekil 3.2.'de Lebit Enerji güneş santraline ait simülasyon sonucu elde edilen enerji akış diyagramı bulunmaktadır. Güneş panelleri $26^{0}$ 'lik bir açı ile yerleştirildiğinde panel yüzeyine gelen ışıma \%12.2 oranında artmaktadır. Horizondan kaynaklanan kayıp \%0.7, yansımadan kaynaklanan kayıp \%2.7, tozlanma ve karlanmadan kaynaklanan kayı \%3 iken gölgelemeden kaynaklanan kayıp $\% 0$ olarak ölçülmüştür. Panel yaşlanma kaybı \%1, panel zayıf ışık kaybı \%0.6, panel sıcaklık kaybı $\% 8.7$, panel yansıma kayb1 \%2, panel uyumsuzluk kayb1 \%1.1 ve doğru akım kablolama kayb1 \%1.5 olmak üzere toplamda \%13.7'lik dize kaybı, \%2.1 inverter kayb1 ve \%1.3 değerinde alternatif akım kablolama kaybı bulunmaktadır. 


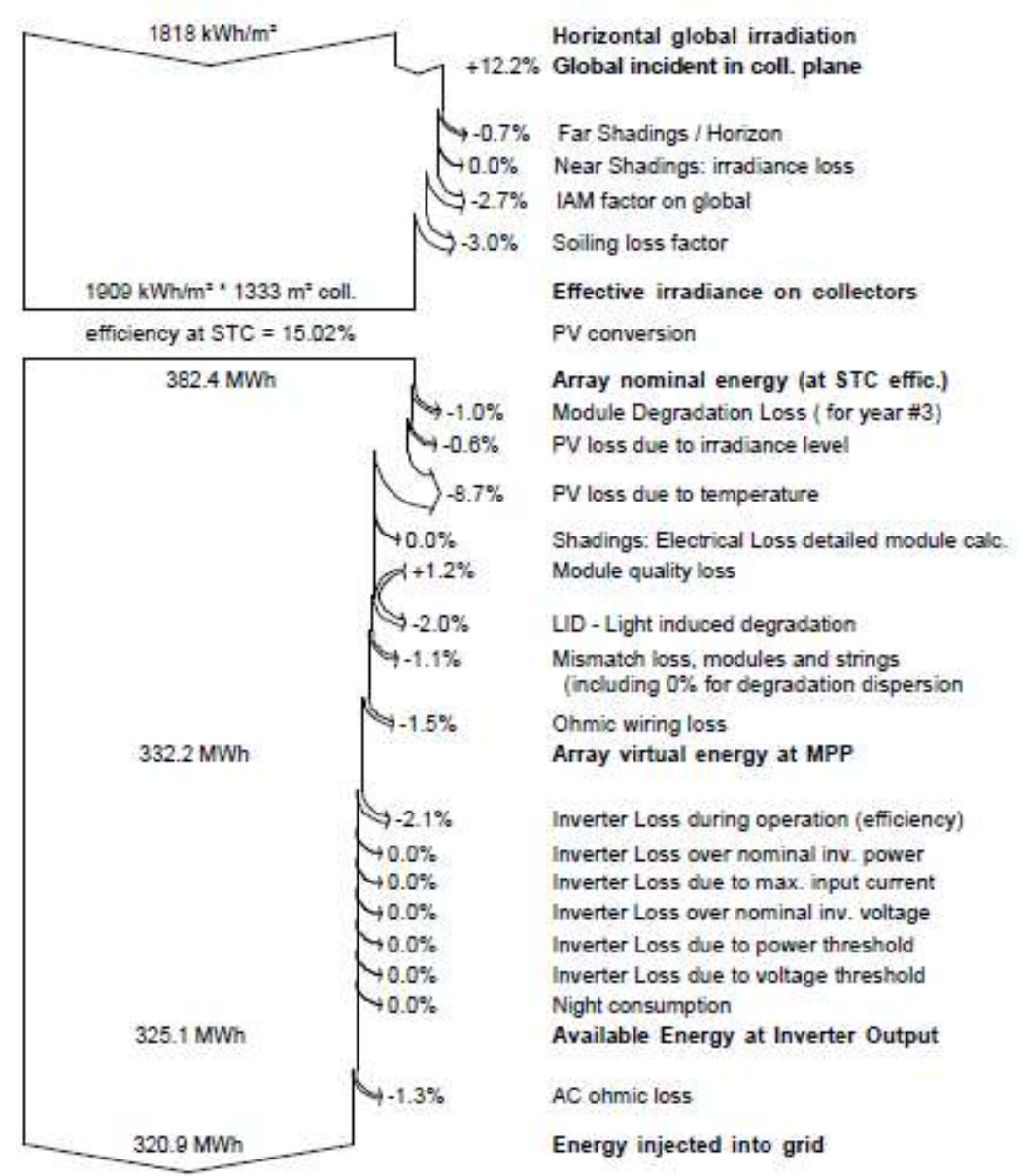

Şekil 3.2. Enerji akış diyagramı

\section{Sonuç ve Öneriler}

PVsyst programı, bir PV sistem kurulumunun tasarımı aşamasında, üreticiye, ilgilendiği coğrafi bölgeye yapılacak olan yatırımının ne kadar sürede geri alınabileceğini, diğer bir ifade ile kara geçiş noktasının tespit edileceği gibi, kurulmuş bir pv sisteminin, revize edilerek optimizasyon çalışmalarında ciddi bir araç olarak kullanılabilir.

Kurulması planlanan PV santrallerinin ayrıntılı olarak simülasyonu adımlar takip edilerek kolaylıkla yapılabilir. PVsyst programını kullanmak isteyenler için, bu çalışma bir kullanım kılavuzu örneği teşkil edebilir.

PVsyst programı kullanıcı dostu bir program olarak altyapısında şu an üretimde olan veya daha önceden üretilmiş olan ekipmanların katalog bilgilerini bulundurmasının yanında tasarım yapılacak ürünlerin de sisteme kaydedilip kullanılmasına izin vermesi programın daha işlevsel kılmaktadır.

PVsyst programı ile kurulacak olan PV sisteminde, maksimum güneş ışımasının elde edilebilmesi için, güneş panelinin açısı tespit edilebilir. Güneş paneli açısının mevsimlik veya aylara göre ayrı ayrı da ifade edilebilmesi, PV sistemlerin yıl boyunca maksimum 1şıma elde etmesine olanak sağlar. Ayrıca, sabit veya hareketli sistemler kullanılarak güneş paneli açısının belirlenmesine de sağlamaktadır.

PVsyst programı ile kurulacak olan PV sisteminde, farklı özellikte (polikristal, thin, vb.) güneş panelleri seçilerek, güneş panellerinin verimliliklerinin karşılaştırılması konulu çalışmalar yapılabilir.

PVsyst programı ile yenilebilir enerji sistemlerinin kullanımının yaygınlaştırılmasının en büyük sebeplerinden biri olan karbondioksit salınımı miktarı da tespit edilebilir.

PVsyst programında, 3 boyutlu çizim özelliği ile gölgeleme kayıplarının hesaplanması sağlanabilmektedir. Yapılan çizimde, Lebit Enerji güneş santralinde gölgelemeden kaynaklanan bir kayıp olmadığı ispatlanmıştır. 
Bu çalışmada, Siirt ilinde, 200kWp kurulu güce sahip olan Lebit Enerji güneş santraline ait bilgiler, PVsyst programı ile birebir olarak analiz edildi. Bir yıllık gerçek üretim değerleri ile PVsyst programı ile elde edilen simülasyon değerleri karşılaştırıldı ve \% 0.56 ' lik çok küçük bir fark ile yakınsadığı gözlemlenmiştir.

Yapılan analiz ve incelemeler neticesinde, düzenli toz ve kar temizliği yapılırsa, daha fazla enerji üretimi sağlanabilir.

PVsyst programı, maliyet hesabını da yapabilen bir program olmasına rağmen, yapılan masraflara ait bilgilere ulaşılamadığından, bu özelliği kullanılamamıştır. Ancak, yeni kurulacak olan bir PV sisteminin üreteceği enerji miktarı kadar, maliyet hesabının yapılması da önemli olduğu için, programın bu özelliği yeni kurulacak olan PV sistemleri için kullanılabilir.

\section{Yazarların Katkısı}

Uğur ARİFĞLU makalenin yürütülmesini organize etmede, ilerlemesini gözetmek ve sorumluluğunu üstlenmede, fikir olarak makalenin hipotezini veya fikrini oluşturmada, çalışmanın teslim edilmesinden önce, dil ve yazınsal düzeltmelerden bağımsız olarak bilimsel anlamda çalışmayı yeniden değerlendirmede; Hamit Kürşat DEMİRYÜREK sonuçlara ulaşılmasını sağlayacak metodu belirleme ve uygun olarak tasarlamada, çalışma için gerekli kaynak taramasında sorumluluk almada, çalışmanın tamamının ya da önemli bölümlerinin yazılmasında; Mehmet BOLAT simülasyonu gerçekleştirilen tesisin gerçel datalarının toplanmasında, verilerin düzenlenmesi ve raporlanmasında, simülasyonların yapılması için sorumluluk almada, elde edilen verilerin mantıklı bir şekilde değerlendirilip karşılaştırılarak sonuçlandırılmasında katkı sağlamıştır.

\section{Çıkar Çatışması Beyanı}

Yazarlar arasında herhangi bir çıkar çatışması bulunmamaktadır.

\section{Araştırma ve Yayın Etiği Beyanı}

Yapılan çalışmada araştırma ve yayın etiğine uyulmuştur.

\section{Kaynaklar}

[1] Yılmaz Ş. 2015. Kahramanmaraş İl Merkezi Koşullarında Optimum Enerji Verimliliğine Sahip Fotovoltaik Temelli Bir Elektrik Jeneratörünün Modellenmesi ve Gerçekleştirilmesi. Doktora Tezi, Kahramanmaraş Sütçü İmam Üniversitesi, Fen Bilimleri Enstitüsü, Kahramanmaraş.

[2] Küçükgöze O.M. 2016. Erzincan İlinde Güneş Enerjili Elektrik Üretim Sisteminin Ekonomik Analizi. Yüksek Lisans Tezi, Erzincan Üniversitesi, Fen Bilimleri Enstitüsü, Erzincan.

[3] Ajder A. 2011. Fotovoltaik Güneş Enerjisi Sistemleri İçin Optimum Eğim Açısının Hesaplanması. Yüksek Lisans Tezi, Yıldız teknik Üniversitesi, Fen Bilimleri Enstitüsü, İstanbul.

[4] http://Globalsolaratlas.Info/ (Erişim Tarihi: 17.12.2017).

[5] http://www.teknosayfa.com/gunes-enerjisi-kullanimi-2016-yilinda-rekor-seviyelere-ulastih391.html (Erişim Tarihi: 17.12.2017).

[6] Kılıç Ç.F. 2015. Güneş Enerjisi Türkiye'deki Son Durumu ve Üretim Teknolojileri. Mühendis ve Makina, 56 (671): 28-40.

[7] https://www.setav.org/dunyada-ve-turkiyede-yenilenebilir-enerji/ (Erişim Tarihi: 17.12.2017).

[8] http://www.eie.gov.tr/mycalculator/default.aspx. (Erişim Tarihi: 17.12.2017).

[9] Haydaroğlu, C., Gümüş, B., 2016. Dicle Üniversitesi Güneş Enerjisi Santralinin PVsyst Ile Simülasyonu ve Performans Parametrelerinin Değerlendirilmesi. Dicle Üniversitesi Fakültesi Mühendislik Dergisi, 7 (3): 491-500.

[10] Rüştü E. 2000. Fotovoltaik Güç Sistemlerinde Performansın Modellenmesi. Yüksek Lisans Tezi, Muğla Üniversitesi, Fen Bilimleri Enstitüsü, Muğla.

[11] Nirwan D., Thakur T. 2017. Performance Evaluation of Grid Connected Solar PV Plant Using Pvsyst. International Research Journal of Engineering and Technology (IRJET), 4 (5): 3190-3194. 
[12] Yadav P., Kumar N., Chandel S.S. 2015. Simulation And Performance Analysis of A Lkwp Photovoltaic System Using Pvsyst. Computation of Power, Information And Communication (ICCPEIC), 3 (5): 358-363.

[13] Tallab R., Malek A. 2016. Predict System Efficiency of 1 MWc Photovoltaic Power Plant Interconnected to the Distribution Network Using PVSYST Software. Conference: 3rd International Renewable and Sustainable Energy Conference (IRSEC), At MarrakechOuarzazate, Morocco, 41-44.

[14] Özerdem Ö.C., Tackie S., Biricik S. 2015. Performance Evaluation of Serhatköy (1.2 MW) PV Power Plant, IEEE, 3 (5): 398-402.

[15] Kandasamy C.P., Prabu P., Niruba K. 2013. Solar Potential Assessment Using Pvsyst Software. IEEE, 5 (6): 667-672.

[16] Soualmina A., Rachid C. 2016. Modeling And Simulation Of 15MW Grid-Connected Photovoltaic System Using Pvsyst Software. IEEE, 7 (6): 9-12.

[17] Raj A., Gupta M., Panda S. 2016. Design Simulation And Performance Assessment of Yield And Loss Forecasting for $100 \mathrm{Kwp}$ Grid Connected Solar PV System. Next Generation Computing Technologies (NGCT), 3 (5): 528-533.

[18] Morshed S., Chowdhury T.H., Rahman A. 2015. Designing of a 2kW Stand-alone PV System in Bangladesh Using PVsyst, Homer and SolarMAT. IEEE, 3 (7): 9-12.

[19] Lalwani M., Kothari D.P., Singh M. 2010. Investigation of Solar Photovoltaic Simulation Softwares. International Journal of Applied Engineering Research Dindigul, 3 (1): 87-92.

[20] Sekçuloğlu S.A. 2012. Fotovoltaik, Rüzgâr ve Hibrit Sistemlerin Tasarimi ve Ekonomik Analizi. Yüksek Lisans Tezi, Karadeniz Teknik Üniversitesi, Fen Bilimleri Enstitüsü, Trabzon.

[21] Bayrak G. 2011. Balık Çiftlikleri Đçin Tasarlanan, Şebekeden Bağımsız, 1.1 kW'lık Kurulu Güce Sahip PV Sistemin Performans Analizi. 6th International Advanced Technologies Symposium (IATS'11).

[22] Yılmaz U. 2008. Gökçeada'da Yenilenebilir Enerji Kaynaklarıyla Elektrik Üretimi. Yüksek Lisans Tezi, İstanbul Teknik Üniversitesi, Fen Bilimleri Enstitüsü, İstanbul.

[23] McGowan J.G., Manwell J.F., Warner C.L. 1996. Hybrid Wind/PV/Diesel Hybrid Power Systems Modeling and South American Applications. Renewable Energy, 836-847.

[24] Bali S. 2015. Güneş Enerjisi Sektöründe Kullanılan Bilgisayar Destekli Simülasyon Programları; PV*SOL Expert Programı İncelemesi. VIII. Yenilebilir Enerji Kaynakları Sempozyumu Bildiriler Kitab1, İstanbul, 127-132.

[25] Çiftçi F. 2016. Güneş Enerji Sistemlerinde Farklı Cins Panellerle Maliyet ve Güç Analizinin Yapılması. Yüksek Lisans Tezi, Bahçeşehir Üniversitesi, Fen Bilimleri Enstitüsü, İstanbul.

[26] Kıyançiçek E. 2013. Fotovoltaik Sistemlerin Boyutlandırılması için Pvs2 Paket Programının Gerçekleştirilmesi. Yüksek Lisans Tezi, Selçuk Üniversitesi, Fen Bilimleri Enstitüsü, Konya.

[27] Lima J.B.A., Prado R.T.A., Taborianski V.M. 2006. Optimization of tank and flate-plate collector of solar water heating system for single-family households to assure economic efficiency through the TRNSYS program. Renewable Energy, 31: 1581-1595.

[28] Gültuna K.M. 2015. Gürsu-Bursa Fotovoltaik Güç Santralinin Simülasyonu Teknoekonomik ve Çevresel Optimizasyon. Yüksek Lisans Tezi, Başkent Üniversitesi, Fen Bilimleri Enstitüsü, Ankara.

[29] Demiryürek H.K. 20178. 200kwp Kurulu Güçteki Lebit Enerji Güneş Santralinin PVsyst ile Tasarımı ve Üretim Değerleri ile Simülasyon Değerlerinin Karşılaştırılması. Yüksek Lisan Tezi, Sakarya Üniversitesi, Fen Bilimleri Enstitüsü, Sakarya.

[30] Şahin M.E., Okumuş H.İ. 2013. Güneş Pili Modülünün Matlab/Simulink ile Modellenmesi ve Simülasyonu. Elektrik Mühendisleri Odası Bilimsel Dergi, 3 (5): 17-25.

[31] Ekici B.B. 2015. Ankara'da teras çatılarda kurulacak fotovoltaik sistemler için optimum eğitim açısının belirlenmesi. 2. Ulusal Yapı Malzemesi Kongresi ve Sergisi Bildiriler Kitabı, Ankara, 437-447. 